\title{
AS INSTALAÇÕES PREDIAIS NO PROCESSO CONSTRUTIVO DE ALVENARIA ESTRUTURAL ${ }^{1}$
}

\author{
MARCO ANTONIO FALSI VIOLANI ${ }^{2}$
}

VIOLANI, M.A.F. As instalações prediais no processo construtivo de alvenaria estrutural. Semina Ci. Exatas/Tecnol,, Londrina, v. 13, n. 4, p. 242-255, dez. 1992.

RESUMO: O presente trabalho trata da racionalização do processo de elaboração dos projetos de instalações prediais hidrosanitárias, elétricas e de gás em edifícios de alvenaria estrutural, identificando o papel que devem assumir no processo, o empreendedor, os projetistas e o construtor. O projeto de instalações foi subdividido em 4 etapas que são: $A$ geração de informações para o início do projeto, o programa de necessidades, o anteprojeto e o projeto para execução. Para cada uma das etapas de projeto são definidos os tópicos que deverão ser analisados, bem como os produtos finais que devem ser apresentados pelos projetistas em cada uma delas. Finalmente, para cada projeto específico apresentamos uma série de soluções que, utilizando-se de componentes especiais e de técnicas construtivas adequadas, permitam a incorporação das instalações prediais à obra com o mesmo grau de racionalização e eficiência obtidos nos demais subsistemas que integram o edifício de alvenaria estrutural.

PALAVRAS-CHAVE: Alvenaria estrutural, instalações prediais

\section{1 - INTRODUÇÃO}

Os processos construtivos de alvenaria estrutural, (P.C.A.E.) que são na verdade processos que o homem vêm empregando ao longo da História a milhares de anos de forma absolutamente empírica, cujo "conhecimento" foi durante séculos transmitido de geração a geração através da prática e no ambiente da "obra" pelos "mestres", tiveram na segunda metade deste século um grande desenvolvimento, ou seja, a alvenaria passou a ser estudada de forma científica, metódica e cujos resultados se constituíram em um novo "conhecimento", que permitiu a sua difusão de forma clara e acessível a profissionais e estudantes.

A evolução dos P.C.A.E. tem se dado através da criação de novas famílias de componentes cuja produção através de processos industriais, permitem a obtenção de produtos com a qualidade desejada. A utilização de tais componentes tem contribuído para se obter ganhos significativos de produtividade e na drástica redução das perdas de materiais. $O$ uso de componentes de concreto (marcos, escadas, rampas, lajes) pré-fabricado incorporados ao processo é crescente, e a produção de lajes de concreto moldadas em loco de forma otimizada, ou seja obtendo-se o acabamento superficial desejado na seqüência do lançamento do concreto, sem a necessidade de nenhum outro revestimento posterior (laje acabada) tem sido largamente empregados por empresas construtoras.

Podemos observar que os P.C.A.E. evoluíram de forma global, ou seja houve uma evolução nos processos tanto ao nível do desenvolvimento dos componentes, como na sua forma de utilização ficando evidente que a diretriz deste desenvolvimento tem sido a construtibilidade. Dentre os subsistemas que compõe o edifício, as instalações prediais de forma geral foram as que tiveram menor evolução, sendo portanto um campo passível de desenvolvimento dentro do processo.

Este trabalho pretende apresentar uma proposta de seqüência de etapas dos projetos de Instalações Prediais dos edifícios de P.C.A.E. com a definição dos conteúdos e propor algumas alternativas tanto na instância de projeto como na sua execução.

\section{2 - O PROCESSO DO PROJETO DAS INSTALA- ÇÕES PREDIAIS DOS EDIFÍCIOS DE ALVE- NARIA ESTRUTURAL}

O projeto completo de um edifício, consiste de um

1 - Trabalho apresentado na disciplina "Tecnologia dos Processos Construtivos de Alvenaria Estrutural II" da Pós-graduação em Engenharia de Construção Civil e Urbana da Escola Politécnica da Universidade de São Paulo, novembro de 1992

2 - Departamento de Arquitetura e Urbanismo/CTU da Universidade Estadual de Londrina, Caixa Postal 6001, Londrina, Paraná Brasil CEP 86051-970 
conjunto de documentos elaborados por profissionais especialistas em diversas modalidades, que tem por objetivo ser a documentação gráfica daquilo que se pretende erigir enquanto objeto físico. A eficácia de um conjunto de projetos pode ser avaliada, confrontando-se estes projetos com o objeto final edificado. O bom projeto é aquele que permite que a obra seja executada seguindose fielmente aquilo que foi proposto pelos projetistas, no prazo estipulado pela programação, ao custo previsto pelo empreendedor e com a qualidade definida nos objetivos do mesmo e incorporada aos projetos pela equipe de projetistas. No processo do projeto do edifício de alvenaria estrutural, o empreendedor, os projetistas e o construtor, tem papéis importantes a cumprir, quais sejam:

a) Ao empreendedor cabe o papel de definir os objetivos do empreendimento, tornando claros seus requisitos de função, operação, condições de comercialização, público alvo, padrão, etc. e a transmissão clara destes objetivos a toda equipe de projetistas e ao construtor.

b) Aos projetistas cabe a responsabilidade de formalizar o produto (edifício) definido preliminarmente nos objetivos do empreendedor, dando-Ihe forma, definindo materiais e processos construtivos a serem empregados de forma a atender ao programa de necessidades e à previsão orçamentária inicial.

c) Finalmente ao construtor cabe a função de materializar o edifício dentro dos prazos, custos e qualidade previstos nos projetos e cronogramas.

Dadas as características próprias dos edifícios de alvenaria estrutural os projetos devem ser elaborados por profissionais que conheçam plenamente o processo construtivo a ser empregado, e cuja experiência profissional atenda às necessidades do projeto. Como neste trabalho trataremos apenas das instalações prediais dos edifícios, apresentamos uma possível seqüência de etapas dos projetos de instalações prediais com os respectivos conteúdos.

\section{1 - INÍCIO DE PROJETO - GERAÇÃO DE INFORMAÇÕES}

Ficha de Informações: Conjunto de informações geradas pelo Empreendedor ou por profissionais contratados e que será fornecida aos projetistas. Os dados que devem constar da ficha de informações são:

\subsection{1 - Características do terreno}

Levantamento planialtimétrico completo com localização de eventuais construções existentes e descrição da infra-estrutura do entorno.

\subsection{2- Relatório de vistoria}

Relatório onde se descreve as reais condições do terreno e do entorno, observados no local.

\section{2- PROGRAMA DE NECESSIDADES}

O programa de necessidades é, em resumo, um elenco de exigências e parâmetros definido pelo Empreendedor onde estão descritos claramente:

- perfil do usuário;

- definição dos ambientes internos e externos, número e dimensões;

- características do processo construtivo a ser empregado;

- padrão de acabamento e custo;

- tecnologia construtiva a ser empregada;

- características das instalações elétricas (número de pontos de luz, tomadas, interruptores, aquecedores etc.)

- características das instalações hidráulicas e sanitárias (tipo de aparelhos sanitários, acabamentos, etc.)

- outros parâmetros de desempenho como, durabilidade dos componentes, níveis de conforto, etc.

Quanto mais elaborado for o programa de necessidades, menor será a possibilidade de improvisação ou decisão sobre questões que não sejam da sua alçada pelos projetistas.

\section{3 - ANTEPROJETO DE INSTALAÇÕES PREDIAIS}

Após a aprovação formal do Anteprojeto Arquitetônico pelo Empreendedor e a partir das informações constantes deste é que terá início o Anteprojeto de Instalações Prediais.

O anteprojeto de instalações prediais é a representação gráfica da solução proposta onde as características das instalações já estejam claramente definidas permitindo inclusive uma primeira avaliação de custos. No anteprojeto serão propostas soluções para:

- instalações para todos os aparelhos indicados no Anteprojeto de Arquitetura (internamente ao edifício);

- instalações externas ao edifício previstas no Anteprojeto de Arquitetura;

- entrada de energia elétrica, água, gás, telefone, coleta de esgoto;

- instalações impostas ou por legislação (combate a incêndio) ou por parte do Empreendedor (captação de sinais de satélite, intercomunicação, circuito fechado de T.V.),

Os anteprojetos de instalações prediais podem eventualmente ser elaborados por uma única empresa projetista o que não é o usual, de qualquer forma o anteprojeto de instalações é composto de diversos anteprojetos específicos quais sejam: 0 de instalações hidráulicas e sanitárias, o de instalações elétricas e o de instalação de gás. 


\subsection{1 - Anteprojeto de Instalações Hidráulicas}

No anteprojeto de instalações hidráulicas e sanitárias serão analisados os seguintes tópicos:

- localização dos pontos de alimentação (cruzado com o Anteprojeto de Arquitetura);

- caminhamento dos ramais de alimentação de água fria;

- caminhamento dos esgotos secundário e primário;

- localização e dimensionamento de elementos como: abrigos para medidores, reservatórios inferiores e superiores, caixas de passagem, "shafts", tampas de visita, canaletas de águas pluviais;

- interferências da execução das instalações hidráulicas e sanitárias com a execução das alvenarias e estrutura;

- possibilidade de produção dos ramais de água fria e esgotos através de "kits" produzidos em canteiro ou central de produção;

- verificação do atendimento dos objetivos do Empreendedor no que se refere ao atendimento do programa de necessidades, previsão de custo, condições de execução etc.

\subsection{2 - Anteprojeto de Instalações Elétricas}

No anteprojeto de instalações elétricas serão analisados os seguintes tópicos:

- caminhamento das redes de distribuição e a sua incorporação no processa construtivo; (forma de colocação e instância)

- número e localização dos pontos de comando e consumo das instalações; (cruzado com o Programa de Necessidades)

- localização e dimensionamento dos quadros de distribuição (QDL), caixas de passagem, medidores e a sua compatibilidade com o processo construtivo, (modularidade, possibilidade de acoplamento a componentes pré-fabricados, etc.)

- interferência com outros elementos do edifício como lajes, escadas, etc.

- possibilidade de produção de parte das instalações em canteiro de obras-ou em central de produção.

\subsection{3- Anteprojeto de Instalações de Gás}

No anteprojeto de instalações de gás serão analisados os seguintes tópicos:

- escolha do tipo de combustível: se "de rua" ou "GLP";

- sistema de medição, se individual ou coletivo;

- número e localização dos pontos de consumo, posição dos medidores;

- caminhamento das tubulações e sistemas de proteção e ventilação;

- interferência com os subsistemas estrutura e alvenaria.

\section{4 - PROJETO PARA EXECUÇÃO DE INSTALAÇÕES PREDIAIS}

É a representação gráfica da solução final das instalações hidro-sanitárias, elétricas, de gás e outras que forem previstas na ficha de informações. Os projetos para execução de instalações nas diversas modalidades devem ser desenvolvidos a partir do projeto para execução de Arquitetura devidamente aprovado pelo Empreendedor ou por outro profissional por este indicado (coordenador do projeto).

Os projetos para execução das instalações prediais, além das peças gráficas de desenho devem conter um memorial descritivo das instalações, memorial de especificação de materiais e serviços, e tendo sido acordado entre as partes (Empreendedor e Projetistas) o levantamento quantitativo detalhado de materiais.

Os projetos para execução das instalações prediais em edifícios de alvenaria estrutural, terão os seus produtos finais (pranchas gráficas de desenho) com o seguinte conteúdo:

\subsection{1 - Produtos finais do Projeto de Instalações Prediais Hidro-Sanitárías}

- planta geral de implantação em escala 1:50;

- planta dos pavimentos e da cobertura em escala 1:50;

- planta e elevações das paredes que contenham instalações na cozinha, banheiros e áreas úmidas com detaIhamento das redes de esgoto e posicionamento das tubulações dentro dos "shafts" em escala 1:20;

- detalhamento do barrilete em escala 1:20;

- detalhamento dos reservatórios em escala 1:20;

\subsection{2 - Produtos finais do Projeto de Instalações Prediais Elétricas}

- planta geral de implantação em escala 1:50;

- planta dos pavimentos e da cobertura em escala 1:50;

- desenhos de paginação (elevação de todas as paredes com instalações elétricas em escala 1:20) com legenda para os diversos tipos de tubulação (telefonia, eletricidade, interfone, etc).

\subsection{3 - Produtos finais do Projeto de Instalações Prediais de Gás}

- localização e detalhamento do abrigo de bujões (GLP) na planta de implantação geral em escala 1:50;

- localização e detalhamento do quadro de medidores (gás de rua) na planta de implantação geral em escala 1:50;

- planta dos pavimentos com caminhamento das tubulações até o ponto de consumo, posicionamento das prumadas e eventuais medidores em escala 1:50;

- detalhes da embutidura das tubulações de alimentação 
dentro de "shafts" com a devida proteção em escala $1: 20$;

- detalhes de chaminés de ventilação em escala 1:20.

\section{3 - CONSIDERAÇÕES SOBRE O PROJETO DAS INSTALAÇÕES PREDIAIS NOS EDIFÍCIOS DE ALVENARIA ESTRUTURAL}

\section{1 - A RACIONALIZAÇÃO DO PROJETO DE INSTALAÇÕES PREDIAIS HIDRÁULICAS E SANITÁRIAS}

\subsection{1 - Distribuição de Água}

A distribuição de água em edifícios normalmente se dá de forma indireta, ou seja, a água da rede pública é armazenada em reservatórios enterrados, daí recalcada para reservatórios elevados e distribuída aos pontos de consumo por gravidade.

Em edifícios de alvenaria estrutural, onde os apartamentos nascem do térreo, a cisterna é externa ao edifício e o sistema de recalque deve dispor de 2 conjuntos de motobombas, um interruptor automático de bóia no reservatório superior e uma chave magnética de proteção na cisterna. Este sistema de distribuição é completada pelo reservatório superior e pelo barrilete.

Em conjunto de edifícios a alternativa mais racional é a de se prever um reservatório elevado único, do tipo castelo, com distribuição direta aos pontos de consumo, eliminando-se os reservatórios elevados dos edifícios, que além de representar um item caro da obra, pois depende entre outras coisas de uma impermeabilização eficiente, além de concentrar uma carga alta no centro do edifício. Oufra economia desta proposta é que um único reservatório enterrado com seu sistema de recalque e proteções é suficiente para alimentar todo o conjunto de edifícios. Outra vantagem é que a manutenção de todo o sistema de armazenamento e distribuição de água é externo aos edifícios não causando transtornos aos usuários.

\subsection{2. - Ramais de distribuição e prumadas de água fria ,}

As possibilidades de posicionamento das tubulações de instalação hidráulica no edifício de alvenaria estrutural são:

a) Em paredes hidráulicas. No edifício de alvenaria estrutural as paredes onde estarão instalados os aparelhos hidráulicos e sanitários são as chamadas paredes hidráulicas que são paredes que não desempenham função estrutural e que portanto podem ser sec- cionadas se necessário for. A fim de se obter uma maior racionalização no processo de execução, o projeto deve convergir para soluções que permitam que as instalações sejam executadas depois de elevada a alvenaria. Uma alternativa para a execução das paredes hidráulicas é a utilização de um bloco especial chamado bloco hidráulico [Figura 1) que é fabricado com ranhuras verticais especialmente para facilitar o rasgo da parede onde serão embutidas as tubulações que podem ser de até $75 \mathrm{~mm}$ de diâmetro. O bloco hidráulico permite também a passagem de tubos na horizontal com diâmetro máximo de 50 $\mathrm{mm}$ em uma cavidade deixada especialmente para isso na sua fabricação.

Normalmente as tubulações que ficarr embutidas na parede hidráulica são as de alimentação aos pontos de consumo (chuveiro, torneiras, vasa sanitário de caixa acoplada e bidê) de diâmetro máximo $25 \mathrm{~mm}$, as prumadas de alimentação devem preferencialmente ser posicionadas em "shafts", solução que será apresentada mais adiante. A seqüência de execução de uma parede hidráulica seria então a seguinte: durante a fase de elevação de alvenaria, as paredes que receberão instalações hidráulicas serão construídas com blocos hidráulicos como sendo uma parede estrutural, após curada a argamassa de assentamento a equipe de instalação hidráulica procederá os rasgos e as embutiduras das tubulações, metais sanitários e a conexão dos ramais de alimentação às prumadas (embutidas em "shafts").

b) Em "shafts": O "shaft" é uma galeria vertical, por onde passam as tubulações verticais, que pode estar apenas no plano da parede ou em outras situações como o "shaft" cuja espessura seja maior que a da parede ou o "shaft" perpendicular ao plano da parede que pode servir simultaneamente dois recintos que utilizem uma parede comum. A grande vantagem da utilização do "shaft" é que ele permite que as tubulações de maior dimensão sejam instaladas com total independência em relação às alvenarias, outra vantagem é a possibilidade de inspeção às instalações ali embutidas.

A interação do "shaft" com as lajes deve ser analisada com muita atenção, pela sua interferência com os elementos estruturais. Para permitir a passagem das tubulações pela laje, é necessário que se faça uma abertura com a mesma dimensão do "shaft". Esta abertura pode ser produzida introduzindo-se na forma da laje um negativo que sirva ao mesmo tempo como referência de nível para o sarrafeamento do concreto. Chamaremos a esta abertura na laje de chaminé. Quando o "shaft" estiver no mesmo plano da parede (Figura 2) o chaminé irá seccionar a cinta de amarração da fiada de respaldo exigindo uma verificação por parte do projetista da estrutura. A solução do "shaft" fora do plano da parede evita o seccionamento da cinta.

No processo construtivo POLI-ENCOL foram desenvolvidos diversos componentes pré-fabricados para a execução dos chaminés de forma racional e incorporada às alvenarias. 

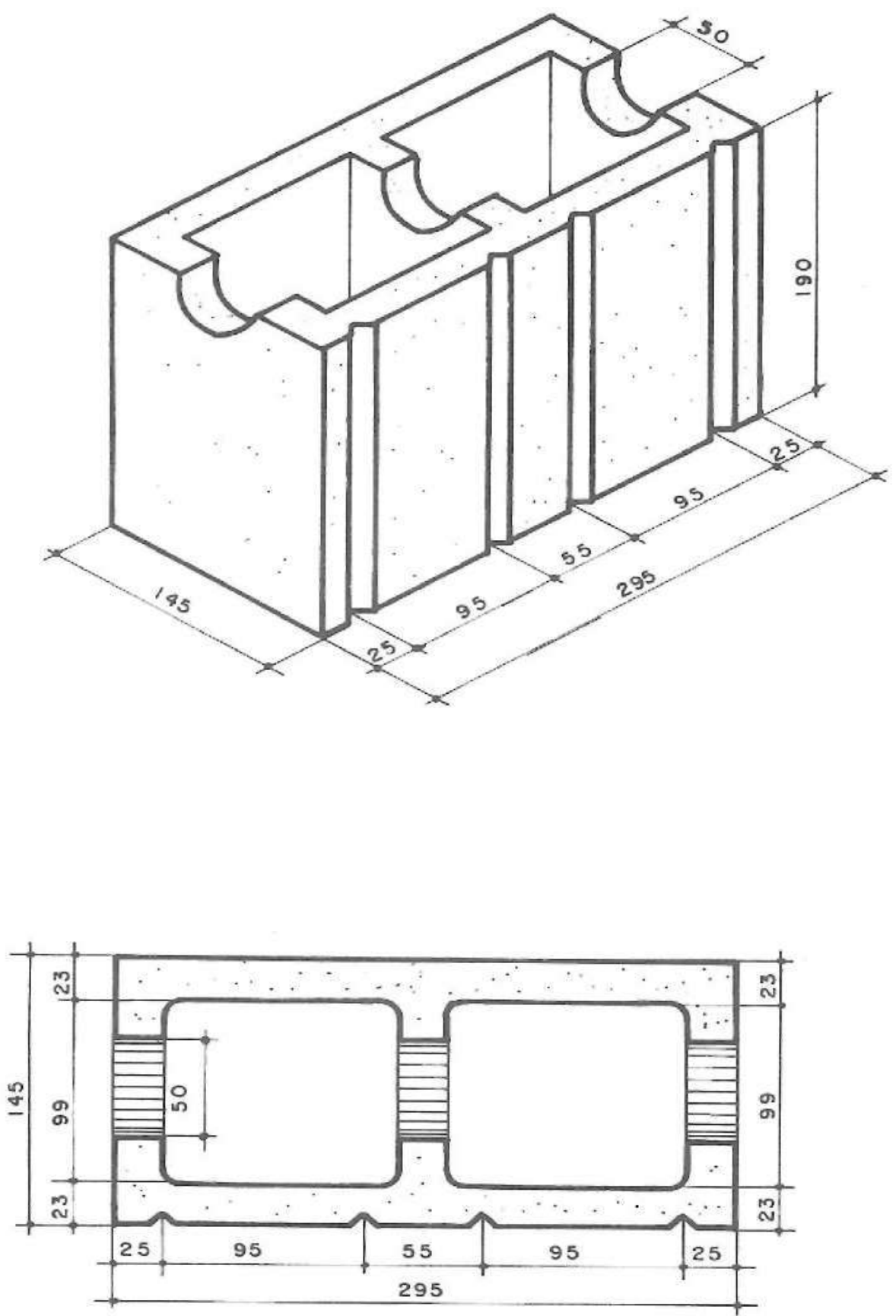

FIGURA 1 - O bloco "hidráulico" proposto para o processo POLI-ENCOL, em perspectiva isométrica e em planta 


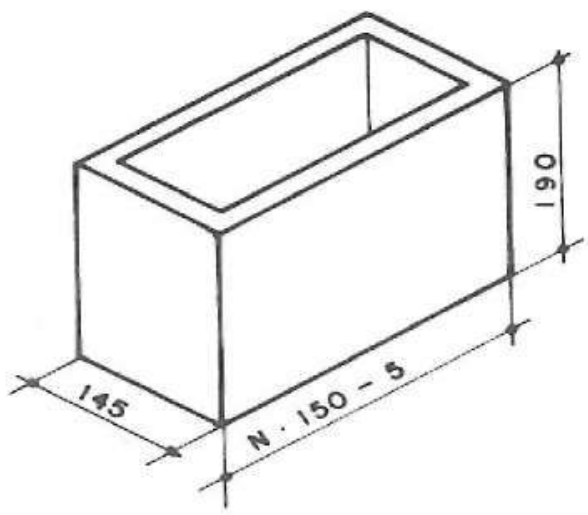

DETALHE GENÉRICO DA PEÇA DE CHAMINÉ MEDIDAS EM MILÍMETROS
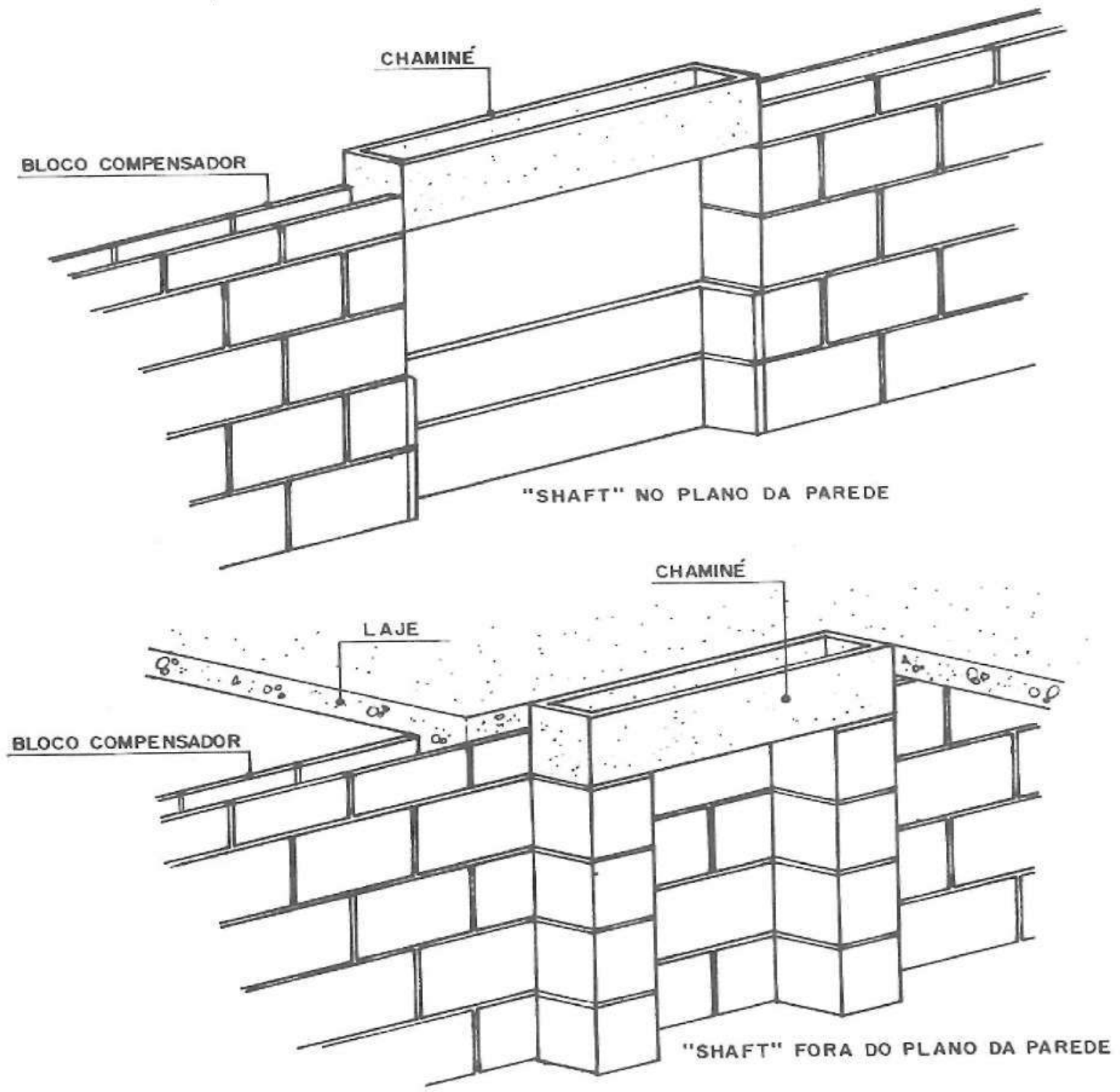

FIGURA 2 - Exemplo de interação do "shaft" com a laje. Um exemplo de "shaft" no plano da parede e outro fora do plano 
c) Embutida: A opção de tubulação embutida na parede é a única que permite que a parede hidráulica possa desempenhar também a função estrutural. No processo de embutidura são utilizados os vazados dos blocos para a passagem da tubulação sem rasgá-los, com a alvenaria na altura de respaldo, é feito um furo na parede no local do ponto de consumo e outro na última fiada, - ramal vertical ê introduzido no vazado do bloco e chumbado ã alvenaria em cima e embaixo (Figura 3 ). No ponto superior deve ser deixado um pedaço de tubo para fora da parede para que seja feita posteriormente a conexão com a tubulação de alimentação que vem do "shaft" e correrá por baixo da laje e acima do forro, Esta solução só permite obviamente a passagem de tubulação vertical com o ponto de consumo na extremidade não permitindo a embutidura de registros de qualquer tipo ou válvula de descarga.

Esta solução pode ser utilizada para a instalação de água fria para lavatórios, vaso sanitário de caixa acoplada e bidês.

d) Enchimento: A solução do enchimento, bastante antiga e praticamente em desuso, consiste em embutir-se as tubulações tanto horizontais quanto verticais em um rebaixo produzido na parede com a utilização de um bloco de menor espessura (por ex. numa parede de $14 \mathrm{~cm}$ utiliza-se um bloco de $9 \mathrm{~cm}\}$. A tubulação é posicionada e fixada, sendo o rebaixo totalmente preenchido com argamassa (Figura 4).

Os inconvenientes da solução de embutidura são:

$1^{\circ}$ - O pedreiro tem que saber ler o desenho da elevação da parede para assentar os blocos de menor espessura na posição correta;

$2^{0}$ - A produtividade da elevação da alvenaria cai drasticamente, pela necessidade de se trabalhar com componentes de diferentes espessura na mesma parede.

\subsection{3 - Água quente}

As recomendações quanto ao posicionamento das prumadas e ramais de alimentação de água fria, valem para a água quente se as tubulações de água quente forem de CPVC, material que dispensa a isolação térmica em torno dos canos. As formas de aquecimento possíveis são as seguintes:

\subsubsection{1 - Aquecedor de passagem individual (elétrico)}

É um sistema de aquecimento em que o aparelho alimenta um único ponto de consumo (lavatório, bidê). A potência destes aparelhos varia de 3 a $5 \mathrm{Kw} / \mathrm{h}$. Necessita de energia elétrica e aterramento. Tem como inconvenientes a pequena potência dos aparelhos disponíveis, que não oferecem água a temperatura ideal no inverno e a manutenção freqüente destes aparelhos.

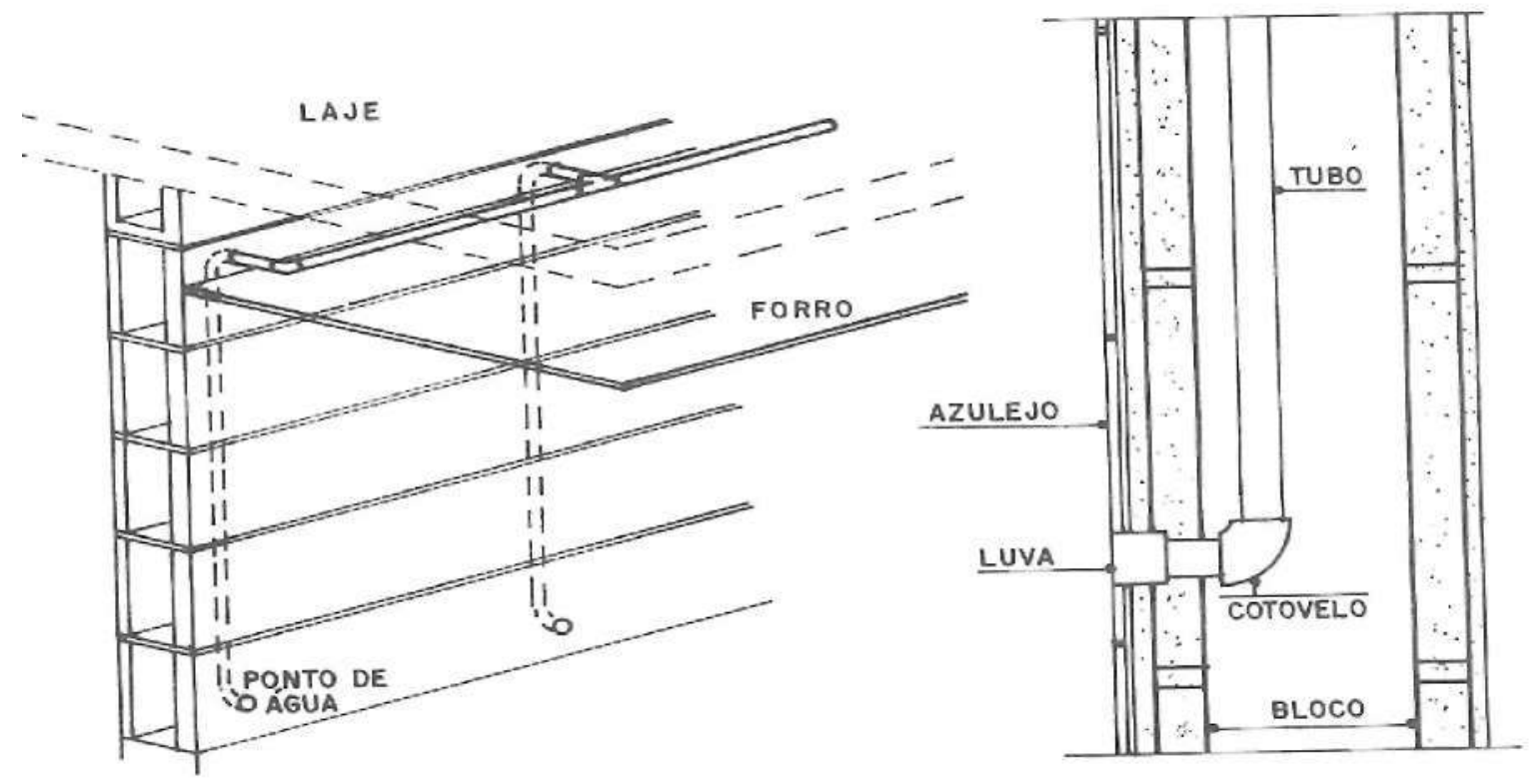

FIGURA 3-Detalhe da solução de instalação hidráulica com tubulação embutida 

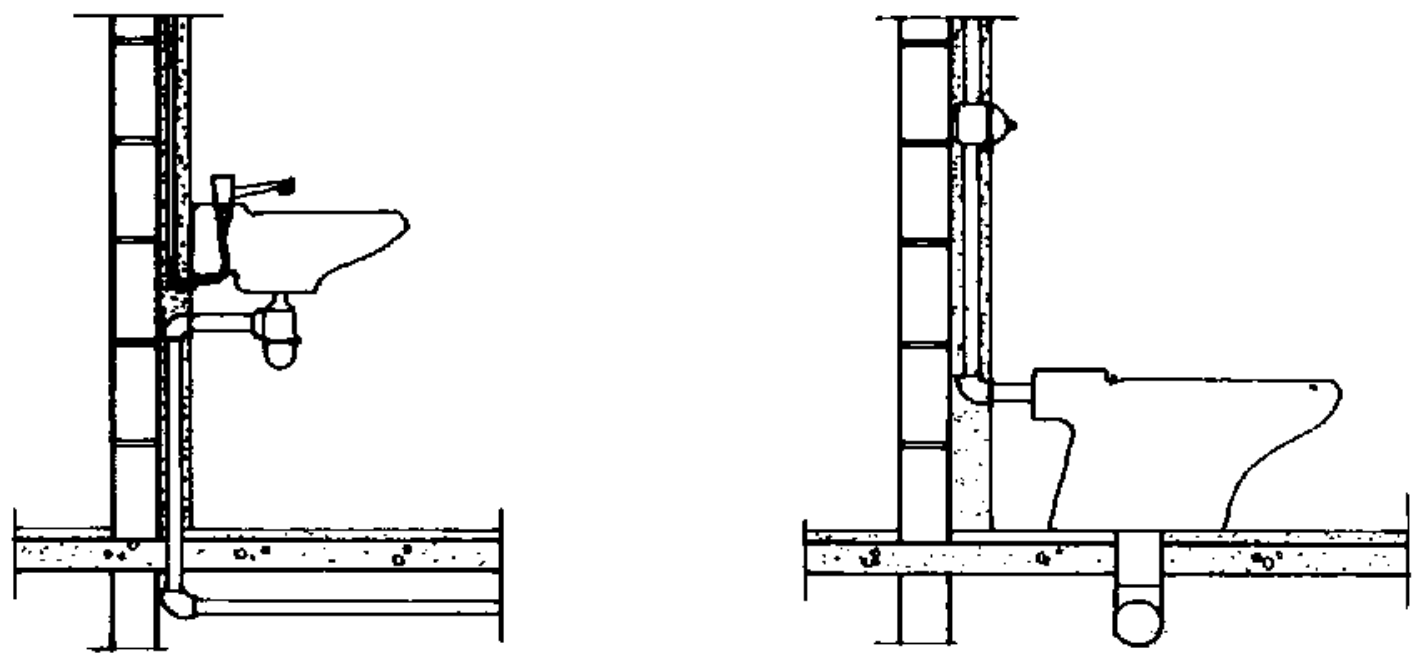

FIGURA 4- Detalhe de instalação hidráulica com enchimento (rebaixo feito com parede e menor espessura)

Este sistema tem como vantagens o baixo custo das instalações tanto hidráulicas (não necessitam de tubulação especial) como elétricas.

\subsubsection{2- Aquecedor de passagem central privado (elétrico)}

Este é um sistema, bastante empregado em residências, em que o aquecedor pode alimentar diversos pontos em um mesmo recinto (chuveiro, lavatório e bidê por ex.). A tubulação que alimenta o aparelho ê de PVC \{água fria) e a distribuição de água quente pode ser de CPVC ou cobre isoiado. A potência instalada deste tipo de aquecedor vai de 7 a $11 \mathrm{~kW} / \mathrm{h}$. Necessita portanto de instalação elétrica e aterramento. A instalação deste sistema tem um custo mais elevado que o de passagem simples, mas o nível de conforto proporcionado é superior. O inconveniente deste sistema é o seu custo de instalação e de operação que é elevado.

\subsection{3- Aquecedor central de passagem privado (gás)}

É um sistema de aquecimento que pode ser instalado desde que o projeto ofereça as seguintes situações:

a) o local de instalação do aquecedor seja ventilado permanentemente e disponha de espaço específico para o aquecedor;

b) o aparelho esteja instalado em uma parede servida por "shaft" e seja divisória do recinto a ser alimentado, minimizando o trecho que necessita de tubulação especial e facilitando simultaneamente a alimentação de gás e água fria e a ventilação através do próprio "shaft";

Os inconvenientes deste sistema de aquecimento são o elevado custo de instalação e de manutenção e a necessidade de espaço para a instalação do aquecedor, a vantagem é o conforto proporcionado.

\subsubsection{4- Aquecedor central privado de acumulação ("boyter")}

É um sistema de aquecimento que pode alimentar diversos pontos de consumo. Necessita de um espaço especifico para a instalação do aparelho, instalação elétrica com aterramento e tubulação especial para água quente. A potência instalada é de 2,5 a $5 \mathrm{~kW} / \mathrm{h}$. Os inconvenientes deste sistema são a necessidade de grandes trechos de tubulação especial, alto custo de instalação e de operação. A vantagem é o conforto proposto.

\subsubsection{5 - Esgoto sanitário}

O esgoto sanitário é dividido em: primário e secundário. O esgoto primário que é a tubulação de descarga que tem acesso a gases da rede pública nasce na saída do ralo sifonado (ramal de esgoto) e é conectado ao tubo de queda, a prumada de descida de esgoto. O esgoto secundário é constituído dos ramais de descarga que recebem os afluentes dos aparelhos sanitários e conduzem ao ralo sifonado também chamado desconectador. As colunas de ventilação do sistema devem se conectar ao esgoto primário após o ralo sifonado e a coluna de ventilação a uma altura pelo menos $15 \mathrm{~cm}$ superior ao ponto de água mais alto da rede hidráulica. O diâmetro da coluna de ventilação não pode ser inferior a $75 \mathrm{~mm}$ (NBR 8160/83). Em edifícios o tubo de queda deve ser prolongado acima da cobertura em pelo menos $2,00 \mathrm{~m}$ e se constituir também num elemento de ventilação da rede de esgoto primário.

Quanto ao posicionamento as tubulações de esgoto primário (tubo de queda e coluna de ventilação) devem estar se possível dentro de "shafts".

A tubulação de esgoto secundário deve se possível atravessar a laje de piso fazer as conexões sob a laje e 
acima do forro falso (Figura 5), como segunda opção caso seja necessário a embutidura do ramal de descarga na parede (lavatório de embutir e pia de cozinha) utilizar o bloco hidráulico com a tubulação na vertical e como última opção a tubulação na horizontal (exceção se o trecho for bastante curto). Do projeto de instalações sanitárias deverá constar o detalhamento da laje indicando a posição e o diâmetro dos furos de passagem de tubulação de esgoto. A possibilidade de produção de kits de instalações sanitárias deve ser considerada no projeto.

\subsection{5 - Águas pluviais}

A configuração de telhado mais racional é a de duas águas com o caimento para fora do edifício. Neste caso a captação das águas se fará por calha de beirai e condutor vertical externo à fachada.

Nos casos em que o projeto exigir que as éguas do telhado tenham caimento para dentro do edifício adotar a solução de calhas em concreto impermeabilizado e condutores embutidos necessariamente em "shafts".

Em terraços a solução preferencial é a de captação com ralo seco embutido na laje e condutor externo apa- rente. A segunda opção (Figura 6) é a do condutor ser embutido em alvenaria, neste caso deve-se utilizar o bloco hidráulico.

\subsection{6 - Combate a incêndio}

As instalações hidráulicas de combate a incêndio consistem basicamente de uma prumada de alimentação e as caixas de mangueira instaladas nos pavimentos. A solução mais racional é posicionar a prumada de alimentação em um "shaft" fechado de alvenaria com a caixa de mangueiras de sobrepor sobre a alvenaria. A segunda opção para edifícios de padrão mais modesto é deixar tanto as prumadas e conjunto de caixa de mangueira aparentes.

\section{2 - A RACIONALIZAÇÃO DO PROJETO DE INSTALAÇÕES PREDIAIS DE GÁS}

As instalações prediais de gás podem ser projetadas para gás de rua ou engarrafado (GLP). Nas cidades onde houver rede pública de gás de rua esta deve ser a primeira opção pela vantagem do fornecimento contínuo.

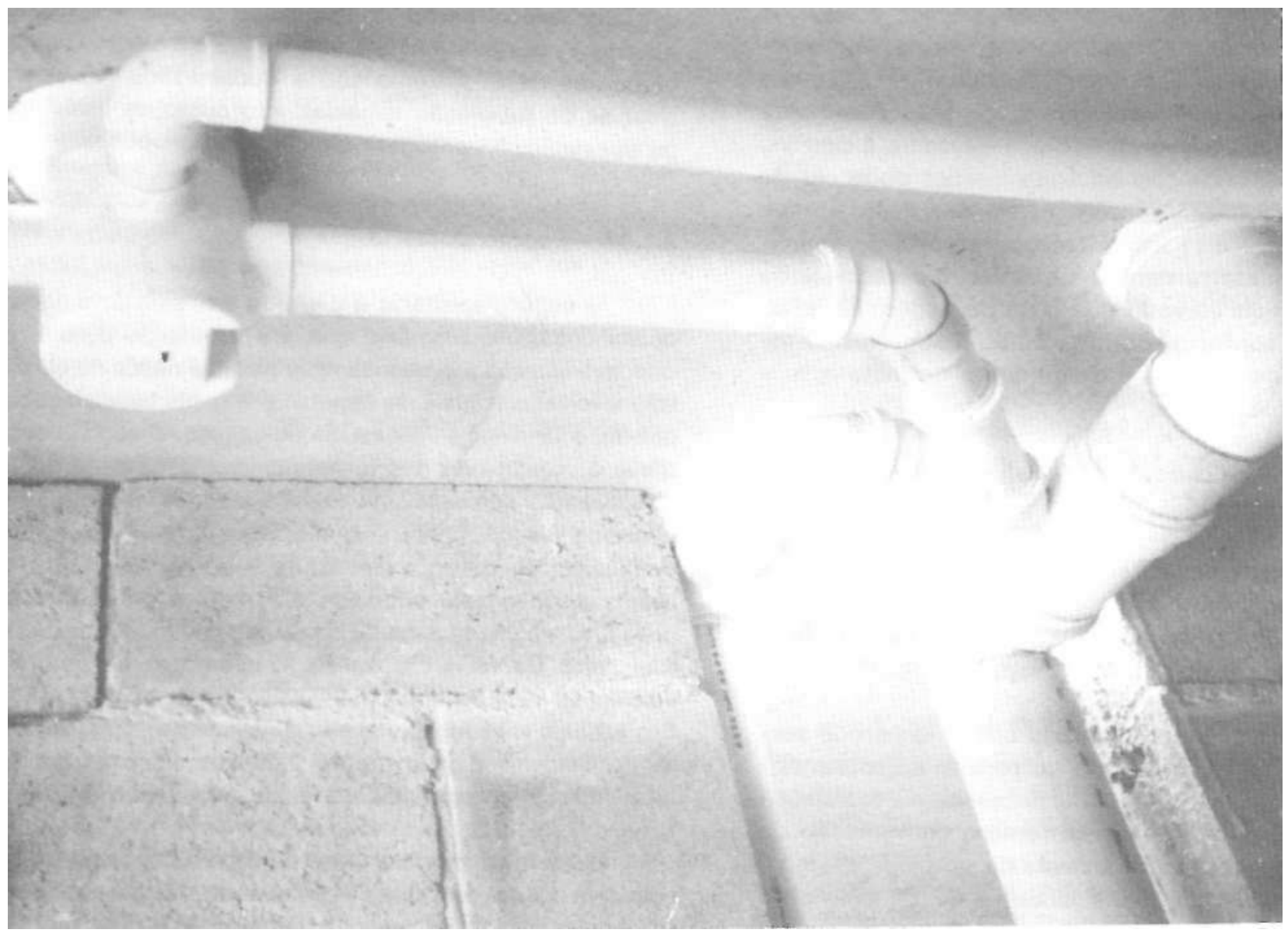

FIGURA 5 - Detalhe das prumadas de esgoto primário em "shafts" e vista de uma rede de esgoto (primário, secundário e ventilação sob a laje de piso) 

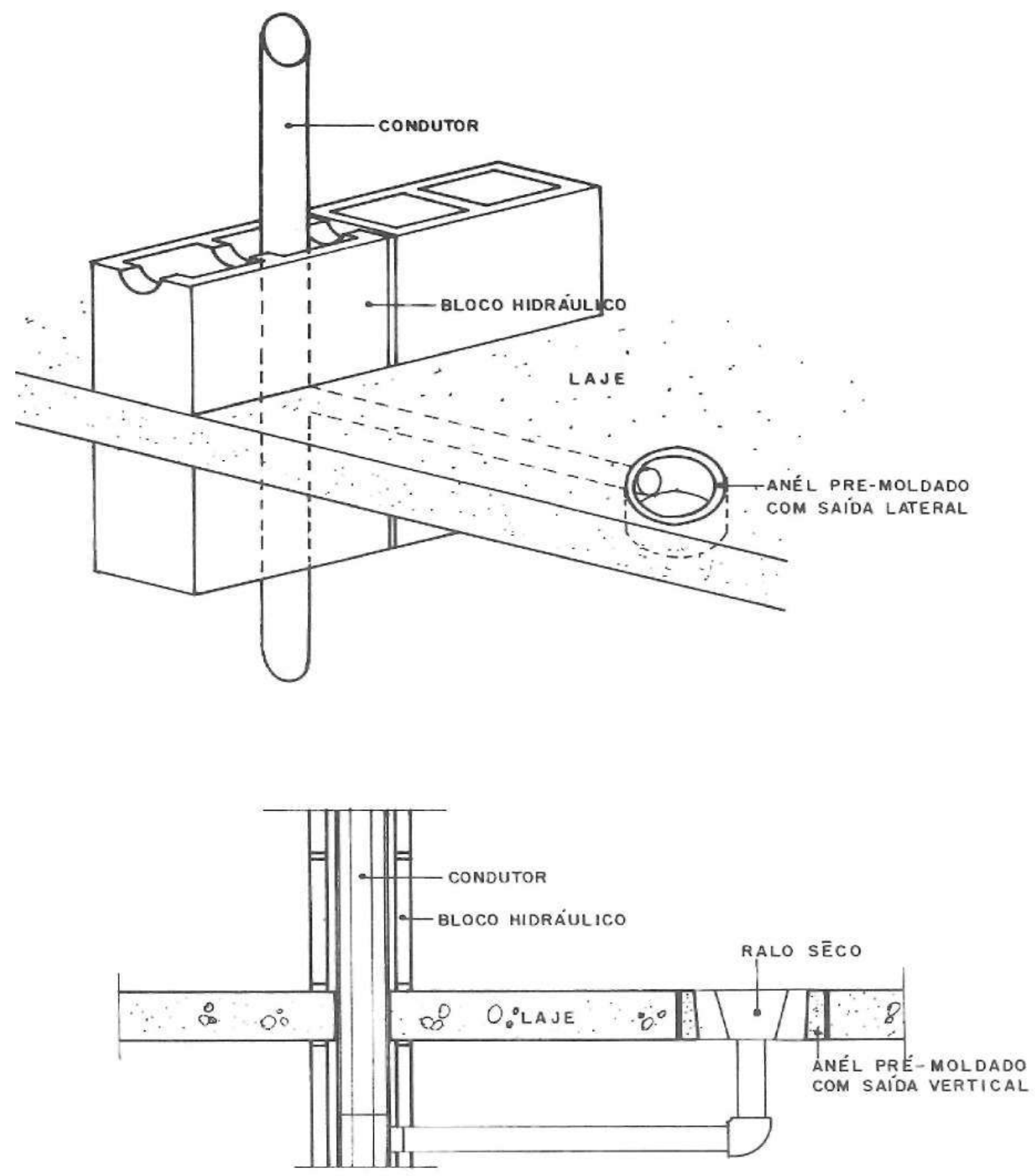

FIGURA 6 - Captação de águas pluviais em terraços

O fornecimento de gás de rua permite a medição individual, que deve ser evitada em função da necessidade de um grande espaço para a instalação dos medidores e ainda de um tubo de alimentação por apartamento que vai do medidor até o ponto de consumo. A medição única deve ser adotada pois permite a distribuição aos pontos de consumo por prumadas.

Onde não for possível a instalação de gás de rua a opção é o GLP. O sistema de medição pode ser individual (medidor instalado no apartamento, próximo ao ponto de consumo, jamais na circulação) o que permite a distribuição de gás por prumadas ou simplesmente não ter medição.

As prumadas de distribuição de gás devem sempre estar dentro de "shafts" (Figura 7) e a tubulação de gás isolada das demais. Deve ser evitada a passagem de tubulação pela laje, quando for inevitável (em pequenos trechos) deve ser prevista a execução de um sulco na mesma cujo detalhe deve constar do projeto. Nas paredes utilizar o bloco hidráulico. 

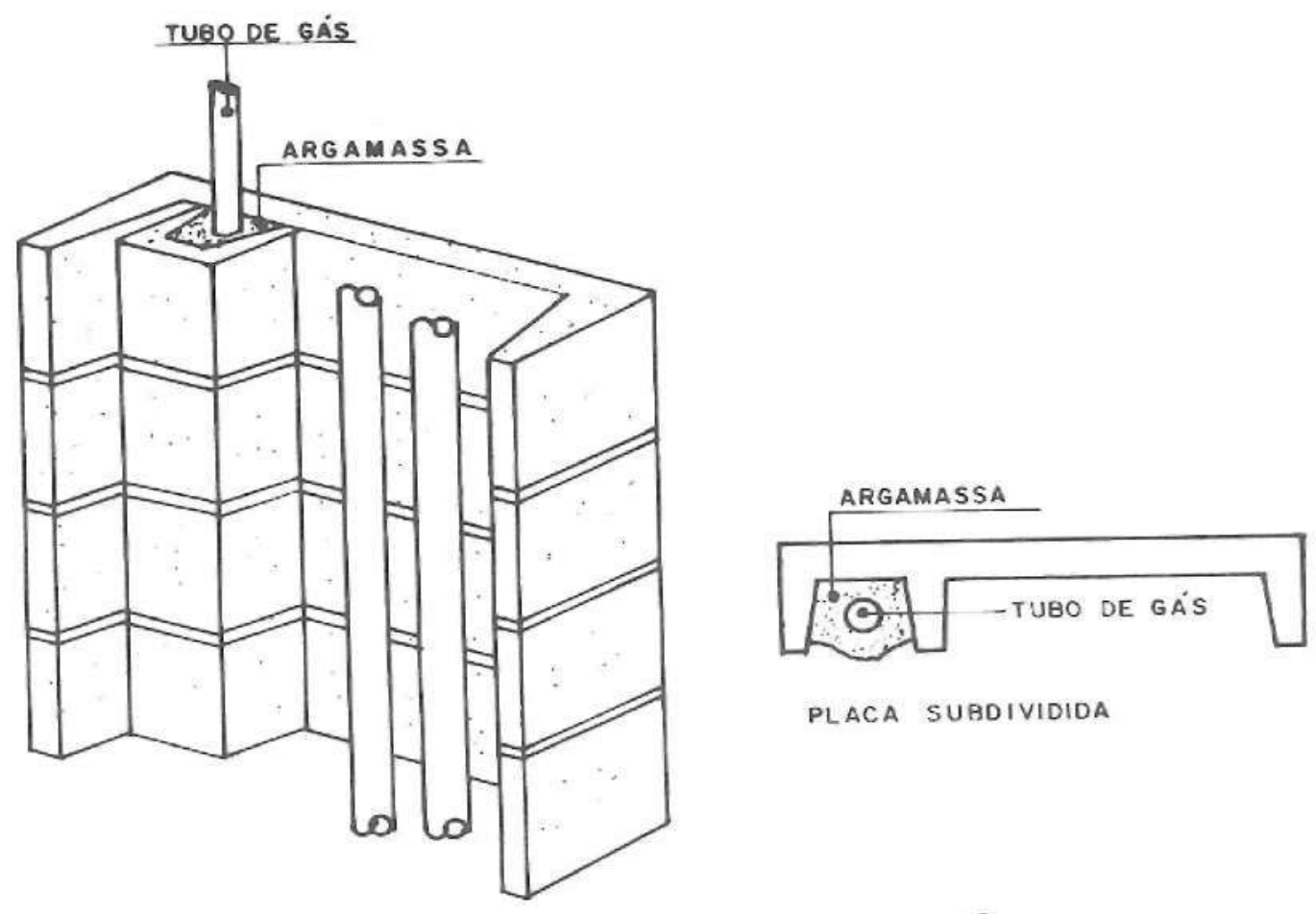

PLACA SUBDIVIDIDA

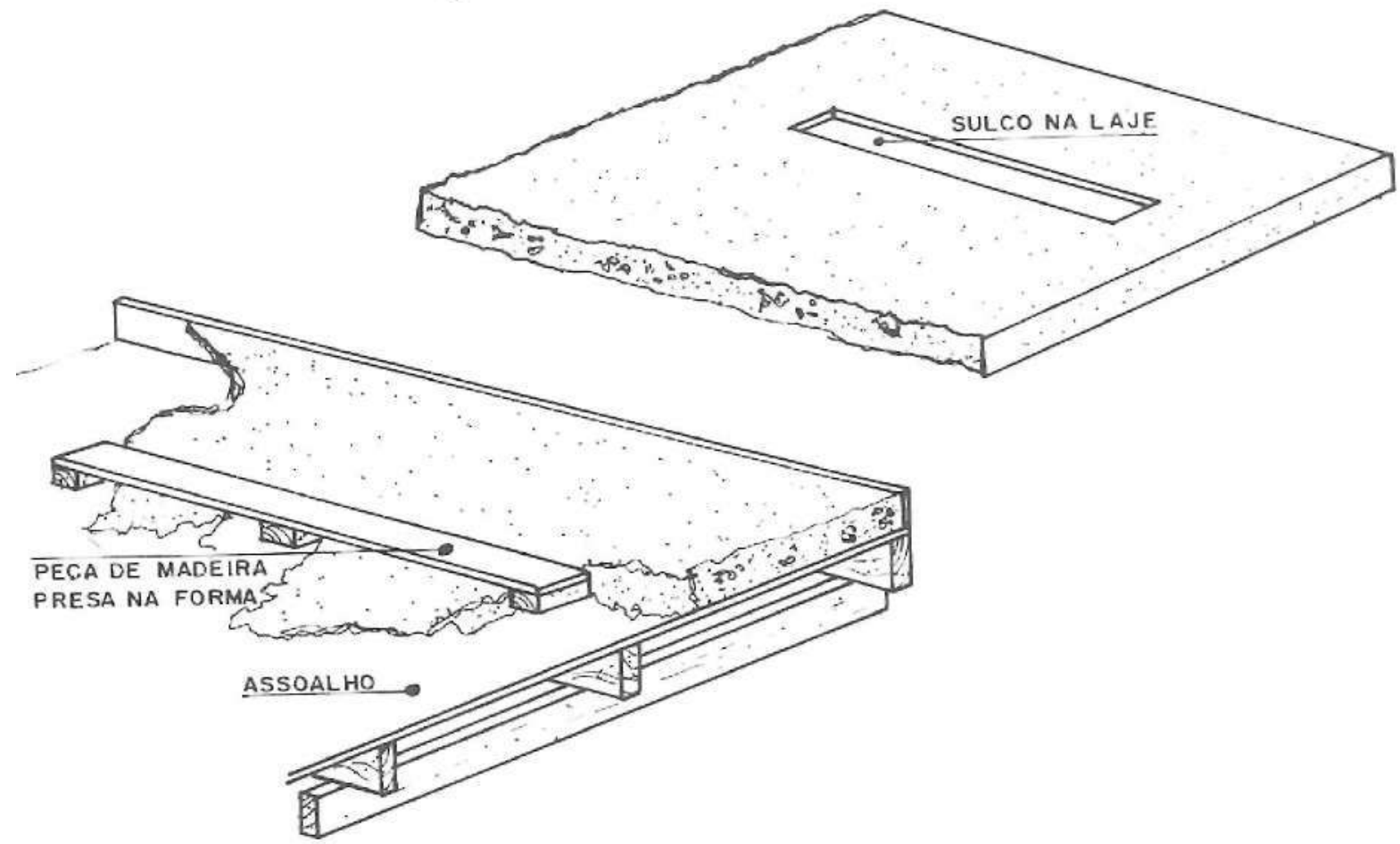

FIGURA 7- Detalhes da isolação da tubulação de gás (prumada de alimentação) dentro de um "shaft" e execução de sulco na laje

\section{3 - A RACIONALIZAÇÃO DO PROJETO DE INSTALAÇÕES PREDIAIS DE INSTALAÇÕES ELÉTRICAS}

As instalações prediais elétricas do edifício de alvenaria estrutural (energia elétrica, telefonia, intercomunicação, T.V. etc) devem ser propostas de forma que possam ser executadas de forma totalmente independente das alvenarias. As formas de posicionamento das tubulações são:

a) nos trechos verticais: dentro dos vazados dos blocos, embutidos em "shafts" ou em paredes hidráulicas;

b) nos trechos horizontais: pela laje ou em paredes hidráulicas.

Semina, Ci. Exatas/Tecnol., v. 13, n. 4, p. 242-255, dez. 1992 


\subsection{1 - PRUMADAS DE ALIMENTAÇÃO (ENERGIA ELÉTRICA)}

São as tubulações vindas do quadro de medidores e que vão alimentar os QDL das unidades. Quando as prumadas estiverem posicionadas dentro de um "shaft" os trechos de eletroduto podem ter uma emenda a cada pé direito. Sendo os eletrodutos embutidos nos vazados dos blocos deve ser utilizado em comprimentos iguais a meio pé direito pois a alvenaria será executada com o eletroduto já posicionado no trecho. Estas tubulações devem transpor as lajes e para isto deve ser utilizado o bloco "chaminé" (Figura 8). Os QDL e caixas de passagem de telefonia, devem ser modulares de modo a se alojarem nas dimensões moduiares dos blocos (Figura 9).

\subsection{2 - PONTOS DE LUZ NO TETO E TOMADAS}

Serão alimentados por circuitos que partem do QDL e chegam até a laje através do bloco "J" ou o "compensador" que serão perfurados com ferramentas específicas permitindo a passagem do eletroduto (Figura 10). Os eletrodutos que vão até os interruptores são passados também através de um bloco perfurado e atingem a altura da caixa do interruptor. As tomadas serão todas alimentadas pelo piso ou seja na fase de montagem da laje o instalador deixa um trecho-de eletroduto $\{+$ ou -30 $\mathrm{cm}$ ) subindo da laje para a parede. Após a concretagem da laje e após a desforma o instalador procede aos rasgos e chumbamentos das tomadas e interruptores cujos eletrodutos já estavam posicionados dentro da parede.

O mesmo procedimento é aplicado às instalações de T.V., interfone e outros.

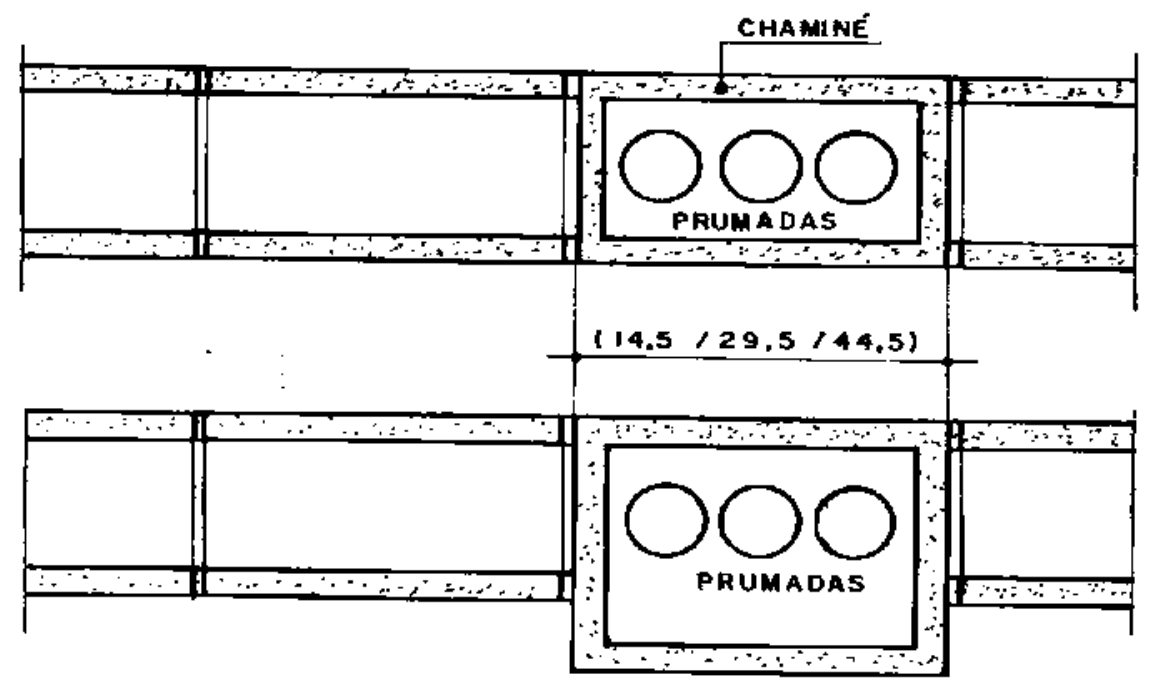

FIGURA 8 - Detalhe do bloco chaminé usado para a transposição da laje pelas prumadas

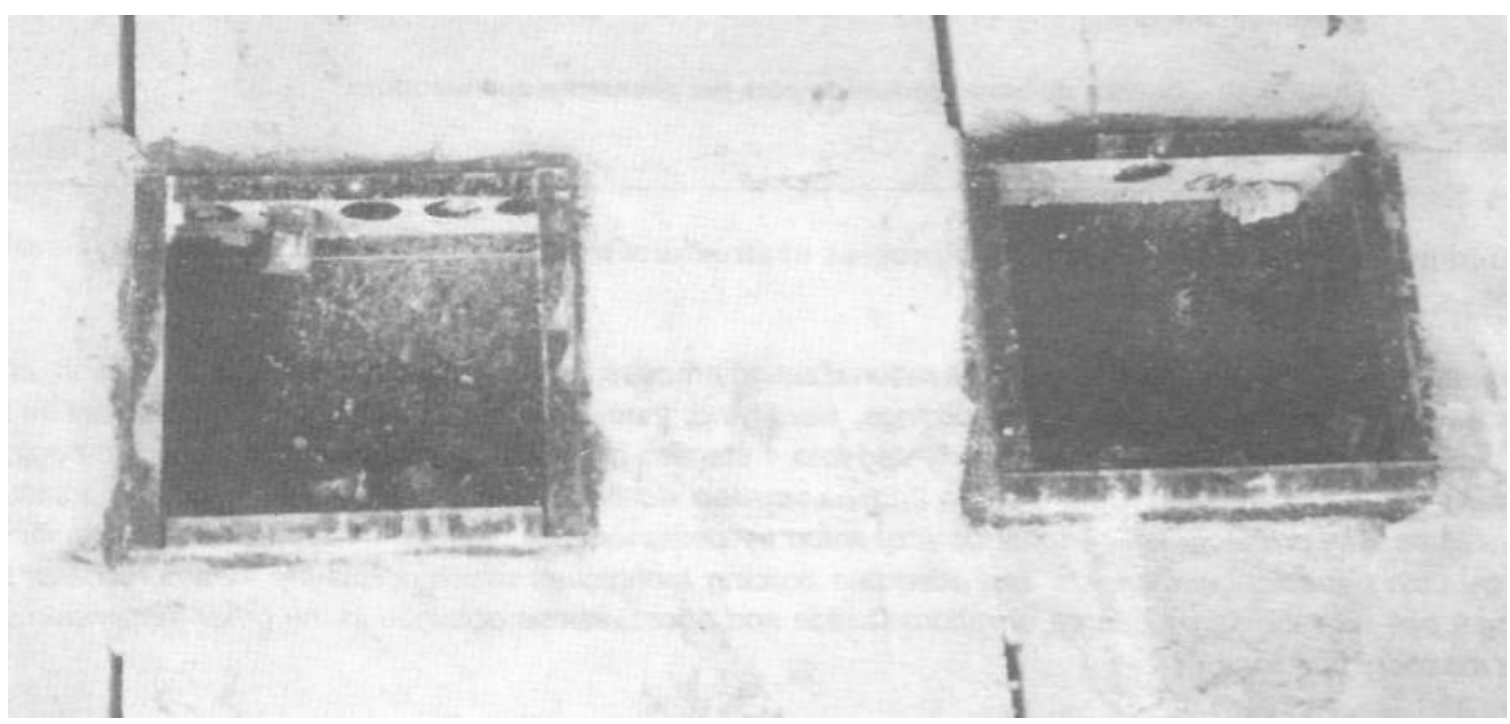

FIGURA 9 - Foto de uma caixa de passagem de telefonia modular 


\section{4-CONCLUSÕES}

A alvenaria estrutural é um processo construtivo que tem conquistado crescentes fatias do mercado habitacional pela sua capacidade de incorporar grande racionalidade construtiva. No entanto, podemos constatar que esta racionalidade construtiva, na maioria das obras executadas por este processo, fica restrita ao subsistem a vedação vertical, e alguns poucos casos à vedação horizontal (lajes), sendo o restante da obra sendo executado praticamente nos mesmos moldes da construção convencional, e neste rol se encontram as instalações prediais.

Uma das formas de se atacar o problema é a utilização de uma metodologia para a elaboração de projetos que considere a especificidade do processo construtivo de alvenaria estrutural e que tenha a "construtibilidade como diretriz".
A segunda é o permanente contata com centros de pesquisa voltados ao desenvolvimento do processo construtivo de alvenaria estrutural, como o Centro de Pesquisa e Desenvolvimento da Construção Civil da Escola Politécnica da USP, que através de Convênios de Pesquisa com a iniciativa privada, tem gerado grande conhecimento nesta área.

O presente trabalho apresenta uma metodologia para a elaboração dos projetos de instalações prediais (hidrossanitárias, elétricas e de gás) e algumas soluções construtivas que, se bem conduzidas no processo do projeto podem conduzir a uma forma de produção de edifícios com maior qualidade e menor custo, minimizando desperdícios de materiais e mão-de-obra e possibilitando a colocação no mercado habitacional de unidades a preço final competitivo.

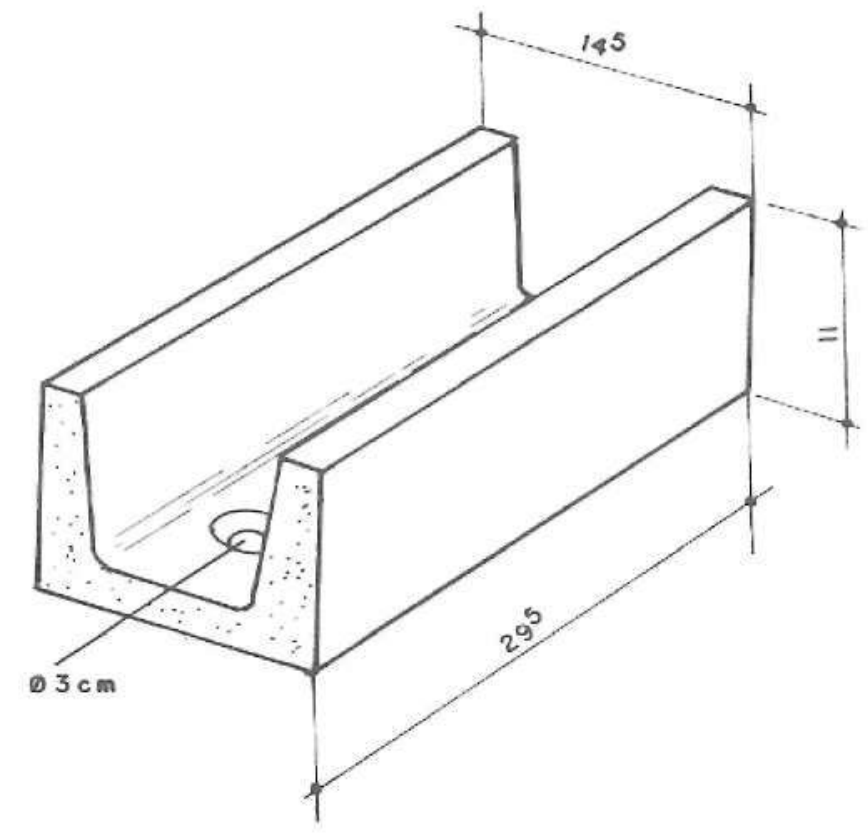

FIGURA 10 - Detalhe do bloco perfurado para dar passagem ao eletroduto

VIOLANI, M.A.F. Building Services in the constructive process of structural masonry. Semina: Ci. Exatas/Tecnol., Londrina, v. 13, n.4, p. 242-255, Dez. 1992.

ABSTRACT: The present research is concerned with the rationalization process in the elaboration of hydro-sanitation, electrical and gas building services design in structural masonry buildings, identifying, thus, their role within the process as well as the role of owners, designers and constructors. The design was divided into 4 stages: generation of information for the beginning of the design; requirement programme, previous design and execution design. For each stage of the design, topics which must be analysed as well as final products which must be presented by designers are defined. Finally, for each specific design we present solutions by using special components and adequate building techniques which permit the incorporation of building services to the building it self with the same degree of rationalization and effectiveness obtained in the other subsystems which integrate the structural masonry buildings.

KEY-WORDS: Building services, structural masonry 
ASSOCLAÇAO BRASILERAA DA CONSTRUÇAOO industrializada. Manual Técnico de Alvenaria, Sso Paulo: Projeto Ectilores Associados, 1992.

BORGES, Ruth Silvelra; BORGES, Wellington Lulz. Manual de instalaçóes Prediais Hidráulico-Sanitárias e de Gás. 3. ed. Belo Morkonte: Edkçüo dos autores.

CONVENOO EPUSP-ENCOL - PROJETO DE PESOUISA EP/EN5. Desenvolvimento de um Nova Processo Construtivo em Alvenaria Estrutural Náo Amada de Blocos de Concreto. Săo Paulo, 1992. Relatórło R5-37/92 - 20.075 INSTALACOEES PREDIAIS.
Manual do Processo Construtivo POLFENCL: Projeto. Sto Paulo, 1991. RelatOrlo Ténko R5-25/91.

CREDER, Hello. Instalaçdes Elstricas 3. ed. Flo de Janeiro: Livros Tónicos o Cientilicos/MEC.

COTPiM, Ademara A.M.B. Instalaçós Elétricas. Fio de Janeiro: Mc Graw-Hill do Brasil, 1980.

TAUIL, Carlos Alberto; RACCA, Cld Lutz Alvenaria Armada. 2. ed. Séo Paulo: Projeto Edtores Assoclados.

Recebido para publicação em 30/06/93 